\title{
A meta-analysis of nutritional supplementation for management of hospitalized alcoholic hepatitis
}

\author{
Ramy Antar MD MSc, Phil Wong MD MSC FRCPC, Peter Ghali MD MSc FRCPC
}

\begin{abstract}
R Antar, P Wong, P Ghali. A meta-analysis of nutritional supplementation for management of hospitalized alcoholic hepatitis. Can J Gastroenterol 2012;26(7):463-467.
\end{abstract}

BACKGROUND: Alcoholic liver disease (ALD) is associated with a high risk of morbidity and mortality. Malnutrition accompanies this condition and may be both a consequence of and contributor to the pathology. Many trials have investigated the benefits of providing supplemental nutrition in the management of patients with ALD. The present study is a meta-analysis of the available evidence.

METHOD: A meta-analysis of randomized controlled studies comparing nutritional supplementation plus a normal hospital diet versus diet alone.

RESULTS: Seven randomized controlled studies including 262 patients with ALD were identified. Pooled analysis revealed no statistical difference in mortality between groups given special nutritional therapy versus a normal balanced diet (OR 0.80 [95\% CI 0.42 to 1.52$]$ ). In addition, nutrition did not significantly improve ascites (OR 1.29 [95\% CI 0.52 to 3.20]) or any biochemical parameters. However, encephalopathy showed a significant improvement or resolution (OR $0.24[95 \%$ CI 0.06 to 0.93]).

CONCLUSION: Nutritional supplementation provided no mortality benefit in patients with ALD, and neither ascites nor biochemical parameters significantly improved. However, encephalopathy was significantly ameliorated and, therefore, nutritional supplementation should be encouraged in that setting.

Key Words: Alcoholic cirrhosis; Alcoholic hepatitis; Encephalopathy; Nutritional supplementation

A lcoholic liver disease (ALD) encompasses a spectrum of hepatic disease that starts with fatty liver, and may progress to hepatitis and fibrosis and, ultimately, cirrhosis. While most cases of fatty liver are reversible with alcohol cessation, alcoholic hepatitis may or may not reverse, and the mortality associated with severe ALD is high (1-3). Therefore, the need for a specific treatment is warranted and, to date, no specific treatment has been found to have a significant impact on the disease $(1,3)$. Most studies have focused on steroids and pentoxifylline, which may provide a modest benefit in severe cases (4-6); however, concerns regarding toxicity and limited efficacy have restricted their general application in clinical practice $(6,7)$. In general, nutritional support has gained wide acceptance in the management of patients with alcoholic hepatitis (7), but its overall effect on outcome remains uncertain.

Patients with alcoholic hepatitis are usually anorexic and malnourished because they substitute calories from food for calories from alcohol. These patients also develop malabsorption from decreased bile production by the affected liver, bowel edema from the low albumin state, mechanical disruption to the gut wall and chronic pancreatitis, which is common in this population $(8,9)$. It has been proposed that the malnutrition that accompanies alcoholism could also add to hepatic injury (10). This can be explained by free radical damage and increased risk of infection, which occur because of a lack of antioxidants, primarily vitamins and amino acids $(9,10)$. Hence, it would

\section{Une méta-analyse des suppléments nutritionnels pour prendre en charge l'hépatite alcoolique chez les patients hospitalisés}

HISTORIQUE : L'hépatopathie alcoolique (HPA) s'associe à un risque élevé de morbidité et de mortalité. Elle s'accompagne de malnutrition, laquelle peut être à la fois une conséquence et un élément contributif de la pathologie. De nombreux essais ont porté sur les avantages des suppléments nutritionnels pour la prendre en charge. La présente étude est une méta-analyse des données probantes accessibles.

MÉTHODOLOGIE : Méta-analyse d'essais aléatoires et contrôlés comparant un régime seul aux suppléments nutritionnels associés à un régime normal chez les patients hospitalisés.

RÉSULTATS : Les chercheurs ont repéré sept essais aléatoires et contrôlés portant sur 262 patients ayant une HPA. L'analyse groupée n'a révélé aucune différence statistique du taux de mortalité entre les groupes ayant reçu une thérapie nutritionnelle spéciale et ceux ayant reçu un régime équilibré normal (RRR 0,80 [95 \% IC 0,42 à 1,52]). En outre, les suppléments n'amélioraient pas les ascites (RRR 1,29 [95\% IC 0,52 à 3,20]) ou les paramètres biochimiques de manière significative. Cependant, les cas d'encéphalopathie se sont considérablement atténués ou se sont résolus (RRR 0,24 [95 \% IC 0,06 à 0,93]).

CONCLUSION : Les suppléments nutritionnels n'avaient aucun avantage sur le taux de mortalité dans les cas d'HPA, et ni les ascites ni les paramètres biochimiques ne se sont améliorés de manière significative. Cependant, les cas d'encéphalopathie se sont considérablement atténués. Par conséquent, il faut encourager l'administration de suppléments nutritionnels dans ce contexte.

seem logical that in addition to alcohol cessation, nutritional support should be of benefit in the treatment of ALD. Nutritional support has been studied in several controlled and uncontrolled clinical trials to estimate its benefcial effect (9-11). These studies have yielded varying results and the power of the controlled studies has been low. The objective of the present systematic review was to assess the effects of nutritional support in patients with alcoholic hepatitis, with or without cirrhosis, with regard to mortality and other parameters.

\section{METHODS}

A systematic review was performed by two independent observers (RA and $\mathrm{PG}$ ), who each searched through the Cochrane, MEDLINE, EMBASE and Google Scholar databases, without restriction on language. A manual search was performed in the major hepatology journals including Hepatology, Journal of Hepatology and Gastroenterology published within the past 10 years and on the references listed by relevant articles. Consensus was achieved for most data, but a third independent observer (PW) was included when disagreement between the observers occurred. The search terms included the following: alcohol liver disease, toxic hepatitis, alcoholic hepatitis, alcoholic cirrhosis, nutritional support and diet therapy. Only randomized clinical trials (RCTs) were included. Also, to limit the potential for publication bias, conference abstracts were sought in the search. The time period of publications was from 1978 until present. Included trials

McGill University Health Centre, Montreal, Quebec

Correspondence: Dr Ramy Antar, McGill University Health Centre, Royal Victoria Hospital, 687 Pine Avenue West, R 2.28, Montreal, Quebec H3A 1A1.

Telephone 514-843-1616, fax 514-843-2421, e-mail peter.ghali@muhc.mcgill.ca

Received for publication October 11, 2011. Accepted November 25, 2011 
TABLE 1

Characteristics and comparability of the included randomized controlled trials

\begin{tabular}{|c|c|c|c|c|c|}
\hline Author (reference), year & Patients, $\mathbf{n}$ & Study days, $\mathbf{n}$ & Experimental nutrition & Route & Control nutrition \\
\hline $\begin{array}{l}\text { Nasrallah and Galambos } \\
(18), 1980\end{array}$ & 35 (18 control, 17 study) & 28 & Amino acids, MVI & Intravenous & Hospital diet \\
\hline Naveau et al (19),1985 & 37 (19 control, 18 study) & 28 & $40 \mathrm{kcal} / \mathrm{BW}, \mathrm{MVI}$, glucose, fat, amino acids & Intravenous & Hospital diet \\
\hline Calvey et al (17), 1985 & $\begin{array}{l}64 \text { (22 control, } 21 \text { conventional } \\
\text { protein, } 21 \text { BCAA formula) }\end{array}$ & 21 & $\begin{array}{l}2000 \text { kcal, carbohydrate, MVI, } 65 \text { g protein } \\
\text { versus } 25 \text { g BCAA + } 40 \text { g protein }\end{array}$ & $\begin{array}{l}\text { Oral or intravenous } \\
\text { (if oral not possible) }\end{array}$ & Hospital diet \\
\hline Achord (22),1987 & 28 (14 control, 14 study) & 21 & $860 \mathrm{kcal}$, amino acids & Intravenous & Hospital diet \\
\hline $\begin{array}{l}\text { Simon and Galambos (20), } \\
1988\end{array}$ & 31 (17 control, 14 study) & 28 & Dextrose, amino acids, lipids, MVI & Intravenous & Hospital diet \\
\hline Bunout et al (23), 1989 & 36 (19 control, 17 study) & 28 & $50 \mathrm{kcal} / \mathrm{BW}$, dextrose, casein (protein), lipids & Oral & Hospital diet \\
\hline Kearns et al (21), 1992 & 31 (15 control, 16 study) & 28 & $167 \mathrm{~kJ} / \mathrm{kg}, 1.5 \mathrm{~g}$ protein $/ \mathrm{kg}$ & Oral & Hospital diet \\
\hline
\end{tabular}

BCAA Branched-chain amino acids; BW Bodyweight; MVI Multivitamins

were required to compare a special nutritional therapy versus a normal balanced diet in hospitalized patients with alcoholic hepatitis. The composition of the nutritional supplementation and the mortality outcomes had to be described. Quality analysis of the retrieved RCTs was assessed by evaluating components such as patient selection, randomization, baseline comparability and reporting of dropouts to assign a score according to the well-validated Jadad scale $(12,13)$. Selected studies were any RCTs judged to be of moderate to high quality according to the Jadad scale (minimum 2 out of 5 ).

\section{Statistical analysis}

Statistical analysis was performed using Review Manager version 5.0 (The Cochrane Collaboration, 2008; The Nordic Cochrane Centre, Copenhagen, Denmark) and GraphPad Prism version 5.0 (GraphPad Software Inc, USA). All analyses were performed on dichotomous outcomes. Pooled ORs with 95\% CIs were calculated using a fixedeffects model. Statistical heterogeneity among studies was evaluated using the $Q$ and $\mathrm{I}^{2}$ tests. An additional funnel plot was constructed to visualize asymmetry and assess for potential publication bias. Subsequent subgroup analysis assessing biochemical changes was also performed. Quantitative data were summarized using the mean and standard error of the mean (SEM). The comparability of the pooled data was assessed using the Mann-Whitney test. In all analyses, $\mathrm{P}<0.05$ was considered to be statistically significant.

\section{Search results}

\section{RESULTS}

More than 3200 results were identified using the search criteria. Of these, 25 articles were accepted based on their titles and abstracts. However, only nine studies met all predefined criteria and were considered to be of sufficient quality for inclusion. The main reasons for exclusion were trials including nonalcoholic cirrhotic patients, nonprospective studies and trials with no mention of mortality outcomes. One additional RCT was found after reading through the references of the eligible studies that was not found in the electronic database searches. Further analysis excluded three additional studies. The first was a nonrandomized prospective study in which patients were recruited from a large cohort study (14). The second study was a randomized study of a high-protein drink versus a placebo pill given to ambulatory outpatient alcoholic cirrhotic patients with decompensated liver disease (15). The patients were seen in clinic biweekly for examination, alcohol level measurement and to renew their nutritional supply. Because this study investigated a different population and was subject to several biases, including failure to assess complete alcohol abstinence, nutritional compliance and other confounding factors, it was deemed unacceptable for the present analysis. The third study was a double-blind RCT comparing intravenous glucose amino acid and vitamin solution versus the same solution devoid of amino acids given to the control group (16). In this case, the control group was different and would affect the pooled data of the meta-analysis. However, all three studies were included in a sensitivity analysis to test the robustness of the results.
Included studies

In total, seven RCTs were identified and reported the random allocation of 262 ALD patients: 138 to nutritional therapy and 124 controls $(17-23)$. The entry criteria in the RCTs were similar and generally of good quality. The diagnosis of ALD was frequently performed by a combination of history of excessive alcohol use, clinical evidence of liver failure, abnormal liver markers, exclusion of other causes and liver biopsies, making it highly likely that all patients did, in fact, have ALD. Liver biopsies were performed in $38 \%$ to $100 \%$ of study participants.

All studies compared the effects of nutritional hyperalimentation with hospital diet alone. All studies provided a normal hospital diet to both the control and experimental groups. The compositions of the nutritional supplements were described in all studies and were similar. The supplements included a mixture of amino acids, vitamins, minerals and provided extra calories in addition to the normal hospital diet. Two studies administered the supplemental nutrition orally, four via the intravenous route, and one study gave the nutrition either orally or intravenously depending on the patient's indication and how well enteral feeding was tolerated. The range of study duration was 21 to 28 days (Table 1 ). In addition to reporting mortality outcomes, almost all of the studies reported other measurements including liver function tests, nutritional assessments and clinical manifestations related to liver failure. Some studies compared these parameters between the groups and over the study period.

\section{Quality of included studies}

The quality of the studies was heterogeneous. With the exception of one study, all studies were blinded, probably because it was obvious to the observers that participants differed in their nutritional management. Randomization was reported in all studies; however, only three studies described their method of randomization, which appeared to be adequate. Comparisons between the study groups' baseline characteristics were described in all of the trials and were similar. Participant dropout occurred in all but one study, with reasons described: mostly because of diet noncompliance, and complications of therapy or of the central venous line. The dropout patients were not included in any study analysis.

\section{Mortality}

Pooled analysis of the seven studies revealed no statistical difference in mortality between the two groups (OR 0.80 [95\% CI 0.42 to 1.52$]$ ) (Figure 1). Repeated analyses with the excluded trials showed a similar result. Causes of mortality were reported in all studies, except one, and appeared to be similar between the study groups. The main causes were worsening liver failure, gastrointestinal bleed, hepatorenal syndrome and infection/sepsis including spontaneous bacterial peritonitis. The funnel plot for the log ORs from the included trials did not demonstrate asymmetry (Figure 2).

\section{Morbidity}

In the three studies that compared clinical manifestations, supplemental oral or intravenous nutrition did not significantly improve 


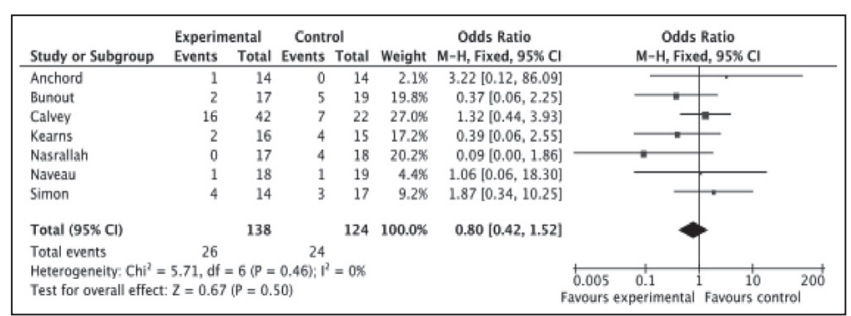

Figure 1) Mortality of patients with alcoholic liver disease from seven randomized clinical trials assessing supplemental nutrition during hospitalization

ascites (OR 1.29 [95\% CI 0.52 to 3.20]). On the other hand, the three studies that evaluated the grade of encephalopathy showed a significant improvement or resolution with nutritional supplementation (OR 0.24 [95\% CI 0.06 to 0.93]). These studies assessed the grade of encephalopathy clinically, and did not administer lactulose or antibiotics as treatment. Patients in these studies who were noted to have encephalopathy at randomization were reassessed at the end of the trial and change of status was documented. Some studies compared the total number of patients with encephalopathy before and after randomization. It was decided not to include these studies because individual changes in encephalopathy were not assessed. Notably, in two of the six studies in which the additional nutrition was given intravenously, catheter-related bacteremia was reported. Naveau et al (19) found positive blood culutres in four of 18 intravenously treated patients.

\section{Biochemical results}

With the exception of one trial, liver function tests and other biochemical markers were measured and compared between groups over the study period. Although there was a tendency toward improvement with nutritional supplementation, these results were not significant. Six of the seven studies compared changes in bilirubin levels $(\mathrm{P}=0.38)$, five studies compared albumin levels $(\mathrm{P}=0.52)$, four studies compared alkaline phosphatase levels $(\mathrm{P}=0.18)$ and three studies compared both alanine transaminase and aspartate transaminase levels $(\mathrm{P}=1.0$ and $\mathrm{P}=0.40$, respectively) (Figure 3 ).

\section{DISCUSSION}

The present meta-analysis was the first to investigate nutritional therapy for alcoholic hepatitis. Nutritional deficiencies are common in patients with ALD, notably because of poor nutritional intake, malabsorption and increased catabolism (9). It has been proposed that the malnutrition that accompanies alcoholism may be related to, and also contribute to, hepatic injury due to a lack of antioxidants and amino acids (8). Our stringent search criteria retrieved data for a pooled total of 124 control and 138 experimental patients, providing a significant study population to detect a significant difference in outcome due to nutritional supplementation. Nevertheless, lack of power remains a limitation in the assessment of small potential differences in mortality. Pooled data from the seven RCTs demonstrated no mortality benefit, albeit with a trend toward survival benefit with supplemental nutrition. Individually, all of the included studies were underpowered, raising the possibility of type II error, especially given that the pooled mortality outcome was low (19\%) (24 of 124). The study by Nasrallah and Galambos (18) was the only one that demonstrated a mortality benefit with supplemental nutrition. Their patient population had alcoholic hepatitis with or without cirrhosis, and was treated with intravenous amino acid infusion and multivitamins plus the hospital diet, and followed for 28 days. Reasons that may explain the survival benefit in that study include selection bias and the intravenous administration of the supplemental nutrition and, hence, avoiding the difficulties associated with anorexia in these patients. However, three other studies followed a similar study design including Anchord (22), who repeated the protocol of Nasrallah and Galambos (18) and used the same nutritional supplementation, but these studies failed to show

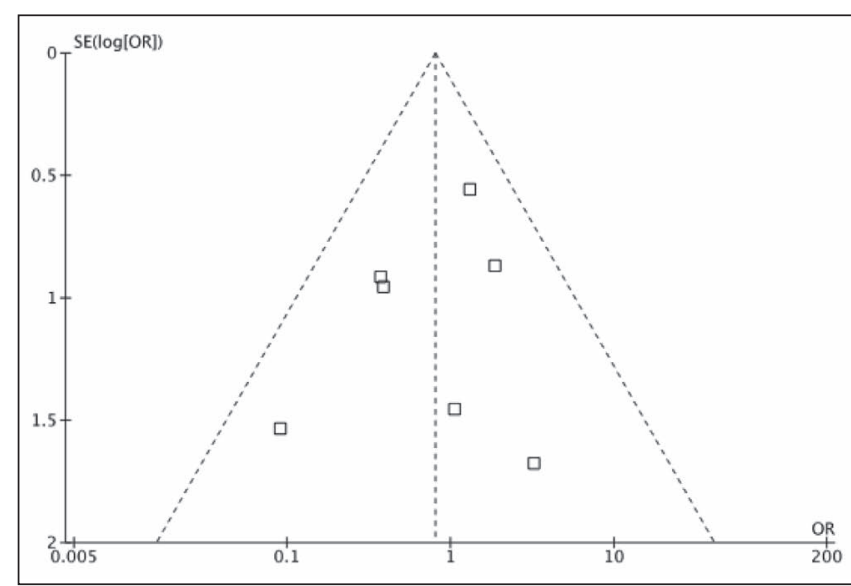

Figure 2) Funnel plot of included trials

mortality benefit. Moreover, of the four studies that requested liver biopsies, Nasrallah and Galambos had a substantially lower number of cirrhotic patients based on biopsy findings (35\% versus $75 \%$ to $100 \%$ ). Thus, ALD may be partially reversible in its earlier stages before progression toward worsening fibrosis and cirrhosis.

Of note, other studies have demonstrated the clear benefits of nutrition for patients with cirrhosis and other forms of liver disease on survival, hospital stay and morbidity $(24,25)$. In a large, randomized multicentre trial, 622 patients with cirrhosis of different causes were randomly assigned to receive branched-chain amino acids (BCAA) with diet versus diet alone (25). The results of this study, which was the largest of its kind, showed a significant reduction in both mortality $(\mathrm{P}=0.015)$ and liver complications, including ascites, edema and encephalopathy, indicated by a significant increase in albumin $(\mathrm{P}=0.018)$ and lower mean blood ammonia levels. Whether this intervention is beneficial in ALD was not evident from our meta-analysis, but neither the population nor the sample size were similar. Likewise, from our included studies, Calvey et al (17) investigated the use of BCAA but also failed to show any mortality benefit over conventional protein or diet therapy alone. However, this study showed that BCAA improved/resolved hepatic encephalopathy and normalized nitrogen balance more than conventional protein or diet therapy.

A limitation of our study is the fact that studies included either enteral or parenteral nutritional support compared with a normal hospital diet. However, the composition of the experimental diet was similar across the different groups in that it included a mixture of amino acids or protein and carbohydrates. Four RCTs added multivitamins to the regimen, but it is unlikely that this would have confounded the overall results. Importantly, all controls and subjects were offered a normal, baseline hospital diet, and the follow-up period was reasonable for short-term mortality. However, data for long-term mortality are lacking.

Our results showed that supplemental nutritional therapy improved hepatic encephalopathy (OR 0.24 [95\% CI 0.06 to 0.93]). In the past, the mainstay of treatment for encephalopathy was to limit the amount of protein in the diet - theoretically, to limit the amount of deamination of protein to aromatic amino acids and ammonia accumulation (26). However, more recent studies demonstrated the beneficial effect of providing adequate amounts of protein during encephalopathy (27) and possibly delivering increased amounts of protein to maintain a positive nitrogen balance if malnourished (28). This led to the 1997 European Society for Parenteral and Enteral Nutrition published consensus guidelines recommending that the daily protein intake in patients with liver disease should, if possible, be approximately $1.0 \mathrm{~g} / \mathrm{kg}$ to $1.5 \mathrm{~g} / \mathrm{kg}$ depending on the degree of hepatic decompensation (29). A randomized study of cirrhotic patients with encephalopathy in 2003 (30) reported no difference between giving low-versus high-protein diet in terms of encephalopathy resolution or mortality, but the low-protein diet group showed higher protein breakdown. 


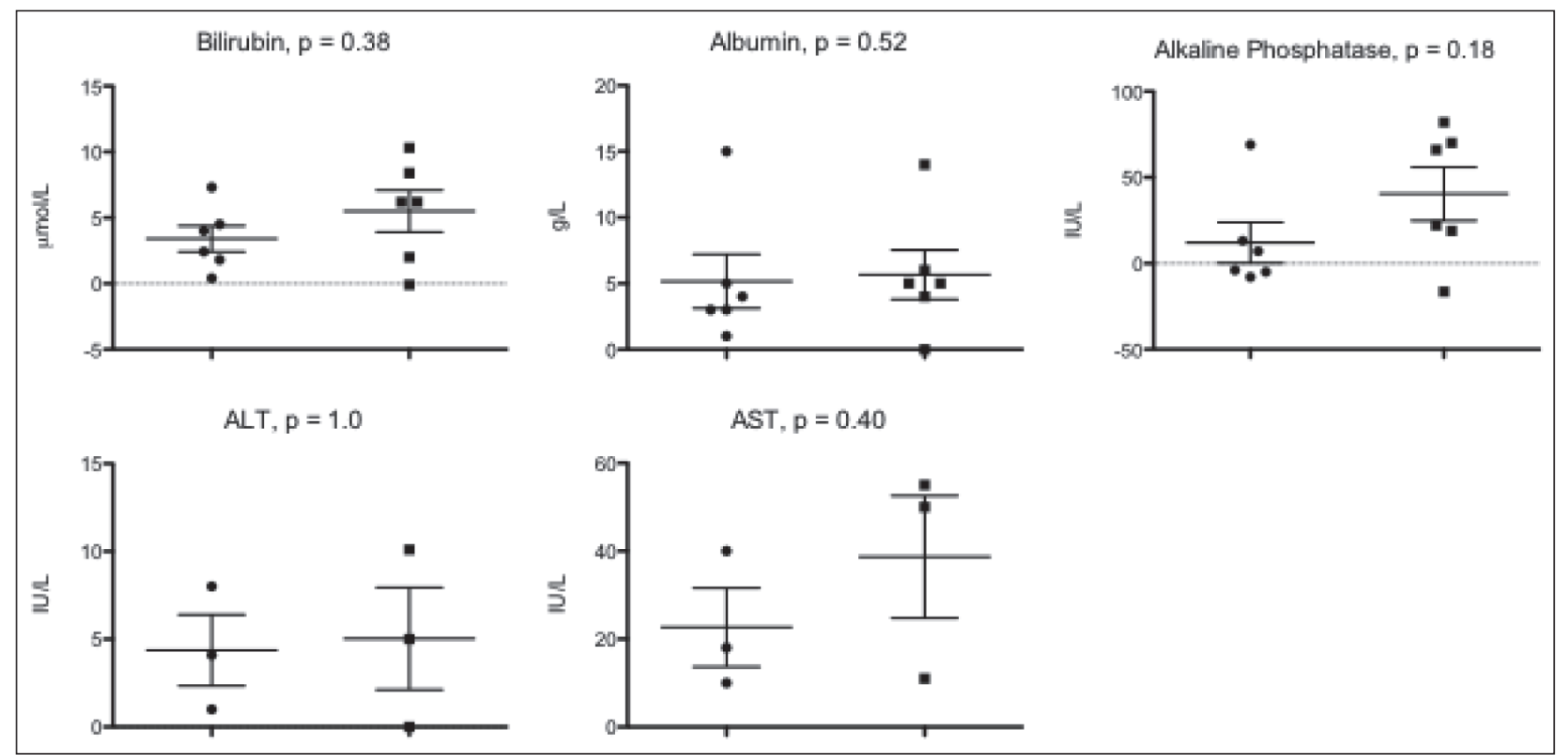

Figure 3) Scatter plots comparing the change in several biochemical markers before and at the end of the study, between the control group (•) and experimental group ( $\mathbf{\square})$. The lines in the scatter plot represent the mean and the SEM. The P value has been provided. ALT Alanine aminotransferase; AST Aspartate aminotransferase

It is not well understood why a high-protein diet might be beneficial in encephalopathy, especially because the pathophysiology of encephalopathy remains unclear; however, ammonia and the overproduction of other neurotoxins is a well-accepted theory $(31,32)$. As a consequence of impaired liver function, other pathways are needed for ammonia clearance. One pathway is the conversion of ammonia to glutamine by muscle (9). A recent study involving rats with acute liver failure and resulting elevations in ammonia levels demonstrated increased glutamine production by skeletal muscle. This suggests that preservation of muscle mass via better nutrition may be beneficial in preventing or ameliorating hepatic encephalopathy and its ensuing complications in patients with ALD (33). Our results and other data suggest that not only can a high-protein diet be safely administered in cirrhotic patients with encephalopathy, but can also be helpful in improving or resolving hepatic encephalopathy.

\section{CONCLUSION}

Malnutrition may be a contributing factor to the morbidity and mortality of patients presenting with ALD. Our meta-analysis of seven studies investigating additional nutritional supplementation for three to four weeks revealed a nonsignificant reduction in mortality. Neither ascites nor liver function parameters improved with the high-protein and high-calorie diet. However, in patients who presented with encephalopathy, there was a significant reduction in its grade or resolution. This evidence further advocates the safety and importance of providing adequate nutrition, including protein, in ALD and hepatic encephalopathy and undermines the concept of protein restriction in these patients.

DISCLOSURES: The authors have no financial disclosures or conflicts of interest to declare.

CONTRIBUTIONS: Ramy Antar: Systematic review and article selection, data acquisition and analysis, drafted manuscript Phil Wong: Study design, critical revision, study supervision Peter Ghali: Study design, systematic review and article selection, study supervision

\section{REFERENCES}

1. Lucey MR, Mathurin P, Morgan TR. Alcoholic hepatitis. N Engl J Med 2009;360:2758-69.

2. Cohen SM, Ahn J. The diagnosis and management of alcoholic hepatitis. Aliment Pharmacol Ther 2009;30:3-13.

3. Tome S, Lucey MR. Review Article: Current management of alcoholic liver disease. Aliment Pharmacol Ther 2004;19:707-14.

4. Whitfield K, Rambaldi A, Wetterslev J, Gluud C. Pentoxifylline for alcoholic hepatitis. Cochrane Database Syst Rev 2009;(4):CD007339.

5. Rambaldi A, Saconato HH, Christensen E, Thorlund K, Wetterslev J, Gluud C. Systematic review: Glucocorticosteroids for alcoholic hepatitis - a Cochrane Hepato-Biliary Group systematic review with meta-analyses and trial sequential analyses of randomized clinical trials. Aliment Pharmacol Ther 2008;27:1167-78.

6. Rongey C, Kaplowitz N. Current concepts and controversies in the treatment of alcoholic hepatitis. World J Gastroenterol 2006;12:6909-21.

7. Cabré E, Rodríguez-Iglesias P, Caballería J, et al. Short- and longterm outcome of severe alcohol-induced hepatitis treated with steroids or enteral nutrition: A multicenter randomized trial. Hepatology 2000;32:36-42.

8. Henkel AS, Buchman AL. Nutritional support in patients with chronic liver disease. Nat Clin Pract Gastroenterol Hepatol 2006;3:202-9.

9. Griffith CM, Schenker S. The role of nutritional therapy in alcoholic liver disease. Alcohol Res Health 2006;29:296-306.

10. Schenker S, Halff GA. Nutritional therapy in alcoholic liver disease. Semin Liv Dis 1993;13:196-209.

11. Bui Han SH. Alcoholic Hepatitis. Curr Treat Options Gastroenterol 2001;4:511-6.

12. Jadad AR, Moore RA, Carroll D, et al. Assessing the quality of reports of randomized clinical trials: Is blinding necessary? Control Clin Trials 1996;17:1-12.

13. Olivo SA, Macedo LG, Gadotti IC, Fuentes J, Stanton T, Magee DJ. Scales to assess the quality of randomized controlled trials: A systematic review. Phys Ther 2008;88:156-75.

14. Mendenhall C, Bongiovanni G, Goldberg S, et al; VA Cooperative Study on Alcoholic Hepatitis. III: Changes in protein-calorie malnutrition associated with 30 days of hospitalization with and without enteral nutritional therapy. J Parenter Enteral Nutr 1985;9:590-6.

15. Hirsch S, Bunout D, de la Maza P, et al. Controlled trial on nutrition supplementation in outpatients with symptomatic alcoholic cirrhosis. J Parenter Enteral Nutr 1993;17:119-24. 
16. Mezey E, Caballería J, Mitchell MC, Parés A, Herlong HF, Rodés J. Effect of parenteral amino acid supplementation on short-term and long-term outcomes in severe alcoholic hepatitis: A randomized controlled trial. Hepatology 1991;14:1090-6.

17. Calvey H, Davis M, Williams R. Controlled trial of nutritional supplementation, with and without branched chain amino acid enrichment, in treatment of acute alcoholic hepatitis. J Hepatol 1985;1:141-51.

18. Nasrallah SM, Galambos JT. Amino acid therapy of alcoholic hepatitis. Lancet 1980;2:1276-7.

19. Naveau S, Pelletier G, Poynard T, et al. A randomized clinical trial of supplementary parenteral nutrition in jaundiced alcoholic cirrhotic patients. Hepatology 1986;6:270-4.

20. Simon D, Galambos JT. A randomized controlled study of peripheral parenteral nutrition in moderate and severe alcoholic hepatitis. J Hepatol 1988;7:200-7.

21. Kearns PJ, Young H, Garcia G, et al. Accelerated improvement of alcoholic liver disease with enteral nutrition. Gastroenterology 1992;102:200-5.

22. Achord JL. A prospective randomized clinical trial of peripheral amino acid-glucose supplementation in acute alcoholic hepatitis. Am J Gastroenterol 1987;82:871-5.

23. Bunout D, Aicardi V, Hirsch S, et al. Nutritional support in hospitalized patients with alcoholic liver disease. Eur J Clin Nutr 1989;43:615-21.

24. Marchesini G, Bianchi G, Merli M, et al; Italian BCAA Study Group. Nutritional supplementation with branched-chain amino acids in advanced cirrhosis: A double-blind, randomized trial. Gastroenterology 2003;124:1792-801.

25. Muto Y, Sato S, Watanabe A, et al; Long-Term Survival Study Group. Effects of oral branched-chain amino acid granules on event-free survival in patients with liver cirrhosis. Clin Gastroenterol Hepatol 2005;3:705-13.

26. Riordan SM, Williams R. Gut flora and hepatic encephalopathy in patients with cirrhosis. N Engl J Med 2010;362:1140-2.

27. Kondrup J, Müller MJ. Energy and protein requirements of patients with chronic liver disease. J Hepatol 1997;27:239-47.

28. Morgan TR, Moritz TE, Mendenhall CL, Haas R. Protein consumption and hepatic encephalopathy in alcoholic hepatitis. VA Cooperative Study Group \#275. J Am Coll Nutr 1995;14:152-8.

29. Plauth M, Merli M, Kondrup J, Weimann A, Ferenci P, Müller MJ; ESPEN Consensus Group. ESPEN guidelines for nutrition in liver disease and transplantation. Clin Nutr 1997;16:43-55.

30. Córdoba J, López-Hellín J, Planas M, et al. Normal protein diet for episodic hepatic encephalopathy: Results of a randomized study. J Hepatol 2004:41:38-43.

31. Dong MH, Saab S. Complications of cirrhosis. Dis Mon 2008;54:445-56.

32. Seymour CA. Dietary management of hepatic encephalopathy. Too many myths persist. BMJ 2000;320:234.

33. Chatauret N, Desjardins P, Zwingmann C, Rose C, Rao KV, Butterworth RF. Direct molecular and spectroscopic evidence for increased ammonia removal capacity of skeletal muscle in acute liver failure. J Hepatol 2006;44:1083-8. 


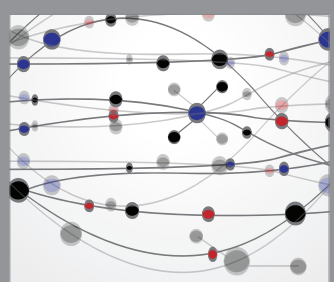

The Scientific World Journal
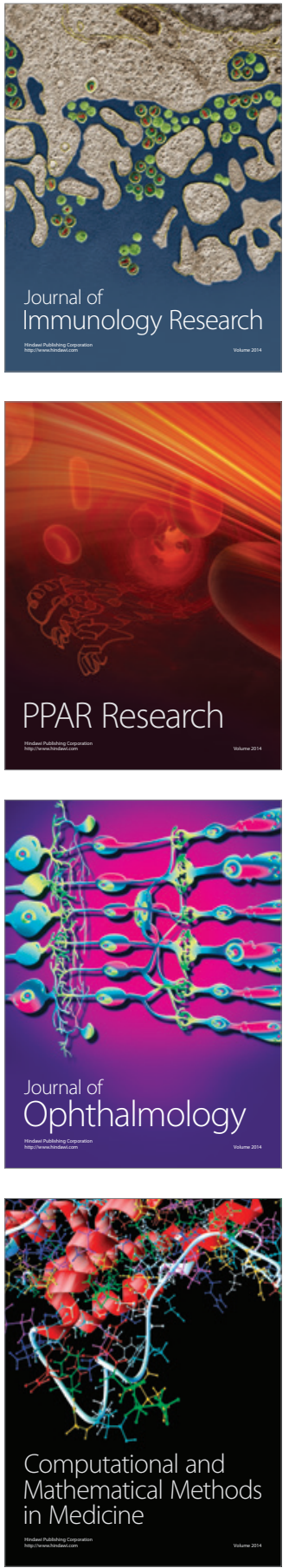

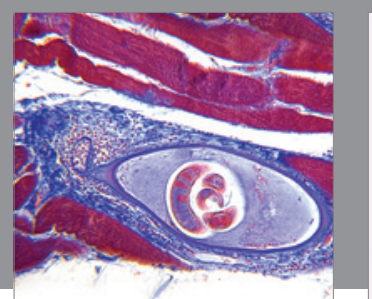

Gastroenterology Research and Practice

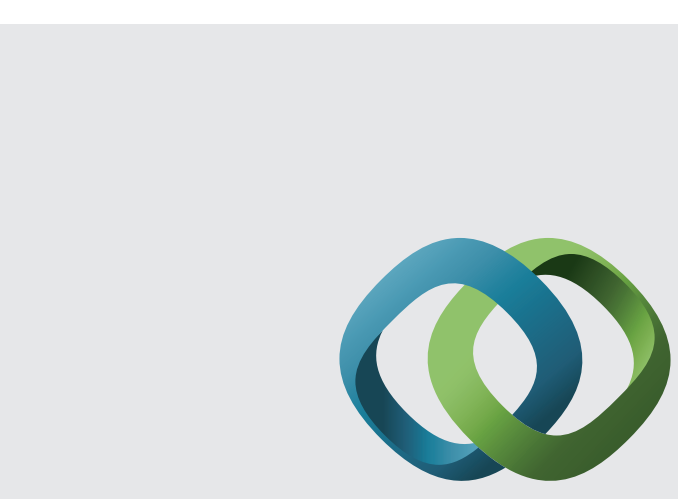

\section{Hindawi}

Submit your manuscripts at

http://www.hindawi.com
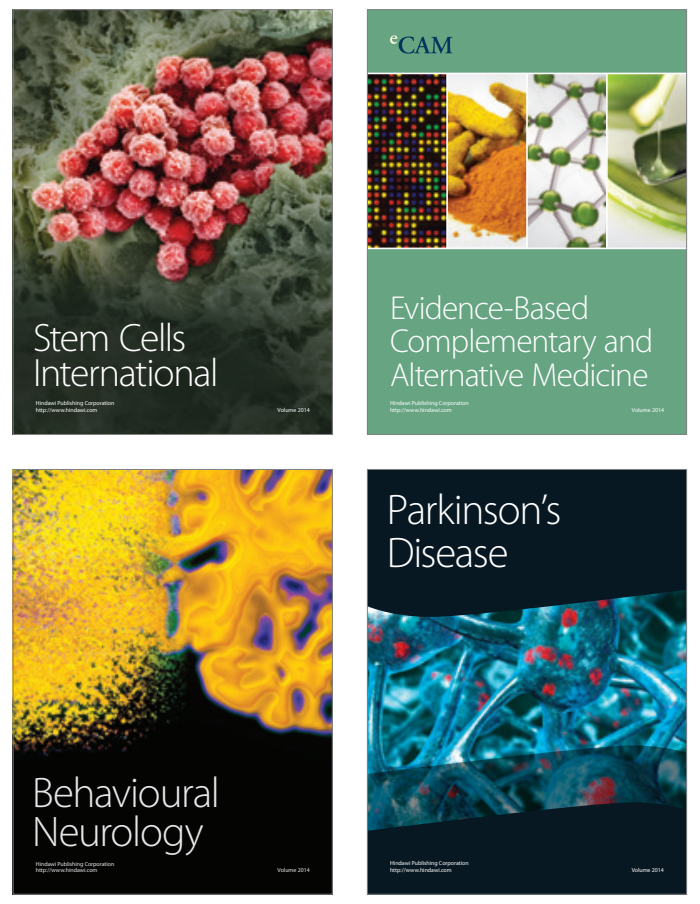
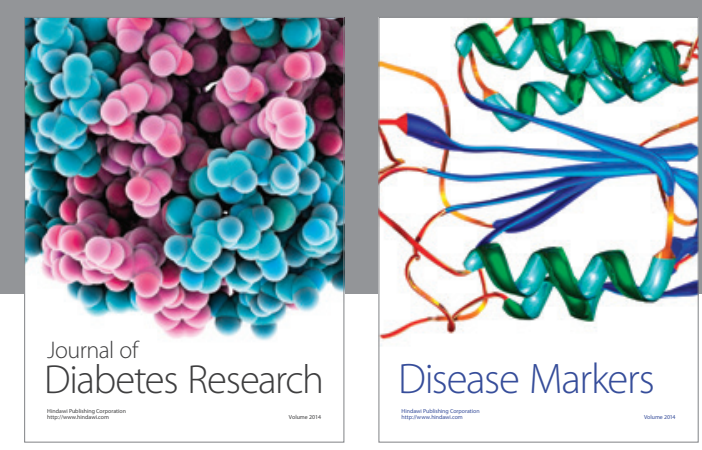

Disease Markers
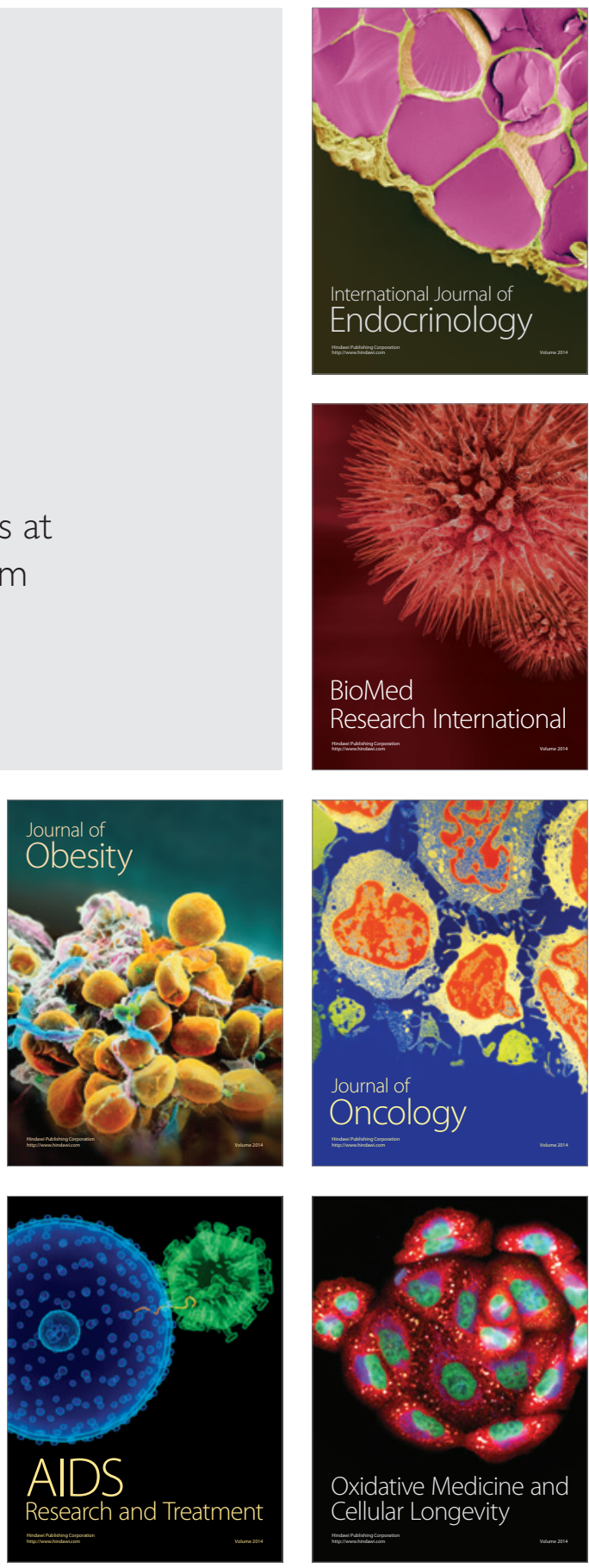